\title{
La formación del capital de marca de un destino turístico a partir de la experiencia turística generada en medios sociales
}

The formation of the brand capital of a tourist destination based on the tourist experience generated in social media

Patricia María Carrasco-García (iD) , Universidad de Granada, España patricarrasco@ugr.es

Dolores María Frías Jamilena (iD, Universidad de Granada, España

dfrias@ugr.es

Ana Isabel Polo Peña (iD, Universidad de Granada, España

apolo@ugr.es

\section{RESUMEN}

Las tecnologías de la información y la comunicación (TICs) como los medios sociales (MS), se posicionan como nuevas vías para la mejora del capital de marca de los destinos. Siguiendo los fundamentos del post-turismo, las TICs constituyen un medio en el que el turista puede acceder a experiencias turísticas previas a la visita del destino. Con este trabajo se pretende conocer si las experiencias turísticas generadas a través de MS son un medio válido para incrementar el capital de marca. Por ello, (a) se propone y se valida un modelo de capital de marca de un destino turístico a partir de experiencias turísticas generadas en MS; y (b) se analizan las relaciones entre las distintas dimensiones del capital de marca del destino turístico. Los resultados ponen de manifiesto que las experiencias turísticas generadas mediante MS son capaces de incrementar el capital de marca de un destino turístico.

Palabras clave: Capital de marca; medios sociales; post-turismo; experiencias turísticas.

\section{ABSTRACT}

Information and communication technologies (ICTS), including social media (SM), have become new ways to improve the brand equity of destinations. Considering the foundations of post-tourism theory, ICTs constitute a means through which the tourist can access tourism experiences prior to visiting the destination. The objective of this study is to determine whether tourism experiences through SM are a valid mechanism to increase brand equity. For this reason: (a) a brand equity model of a tourist destination generated from tourist experiences through SM is proposed and validated, and (b) the relationships existing between 
the different dimensions of brand equity are analysed. The results show that tourism experiences through SM are capable of increasing the brand equity of tourist destinations.

Keywords: Brand equity; social media; post-tourism; tourist experiences.

\section{INTRODUCCIÓN}

La globalización y la gran competitividad que caracterizan el mercado turístico actual, ha llevado a los destinos a implementar fórmulas innovadoras que les permitan la consecución de ventajas competitivas (Muñoz-Guarasa y Moral-Pajares, 2019; Neuhofer et al., 2014), y la atracción de visitantes (Marasco et al., 2018).

Una variable clave para la competitividad de un destino turístico es la gestión de la marca a través de conceptos como el capital de marca, considerado por la literatura como una importante fuente de ventajas competitivas y por ende de diferenciación (Boo et al., 2009; Keller, 2003; Wong, 2018). La literatura sobre gestión de marca, propone el modelo de capital de marca bajo la perspectiva del cliente (CBBE: Consumer Based Brand Equity), como un potente instrumento para que los responsables de un destino turístico puedan evaluar las percepciones que tiene el turista acerca del mismo (Pike y Bianchi, 2016).

Cuando se trata de mejorar el capital de marca resulta necesario considerar las posibilidades que ofrecen las nuevas tecnologías de la comunicación y la información (TICs), como los medios sociales (MS) (Avila Campoverde y Ugalde, 2020; Barreda, 2014; Királ'ová y Pavlíčeka, 2015). Estas plataformas online se han convertido en importantes herramientas para la promoción del destino y la interacción entre éste y el visitante (Sánchez Jiménez et al., 2020; Zeng y Gerritsen, 2014). Además, los contenidos generados en MS, son capaces de hacer que el turista viva experiencias turísticas (Gretzel y Jamal, 2009; Tussyadiah y Fesenmaier, 2009), sin necesidad de un desplazamiento real o físico al destino, tal y como propugnan las teorías del post-turismo (Feifer, 1985; Ritzer y Liska, 2004; Urry, 1988). Los contenidos sobre un destino turístico, son capaces de desencadenar en el individuo el llamado "transporte narrativo" (Escalas, 2004), es decir, que el espectador se sumerja en ellos de tal manera que acabe sintiéndose transportado al destino turístico en sí, sin que exista desplazamiento físico alguno (Tussyadiah y Fesenmaier, 2009). En este contexto, el post-turismo se alza como una nueva modalidad de turismo que se apoya en el uso de las TICs para influir en el comportamiento del turista, como en la intención de visitar el destino (Choi, 2014; Marasco et al., 2018).

Esta capacidad de los MS para facilitar experiencias turísticas (Neuhofer et al., 2014; Sigala, 2016), así como su influencia en la formación del capital de marca (Barreda, 2014; Bruhn et al., 2012; Keller, 2016; Kim y Ko, 2012; Seo y Park, 2018; Stojanovic et al., 2018), aún no ha sido suficientemente estudiada por la literatura. Excepciones a esto último, son las aportaciones realizadas al ámbito del turismo por Barreda (2014), Bruhn et al. (2012), Seo y Park (2018) o Stojanovic et al. (2018). Barreda (2014) plantea un modelo de formación del CBBE en redes sociales turísticas, en el que se analiza cómo la interactividad propia de dichas plataformas influye en la formación del capital de marca. Por su parte, Bruhn et al. (2012) analizan si el impacto de las comunicaciones que llevan a cabo las marcas de forma offline $u$ online, difieren a la hora de influir sobre el CBBE, para ello emplearon marcas procedentes de sectores diversos (el turístico, el de las telecomunicaciones y el farmacéutico). Seo y Park (2018), estudian cómo los componentes de entretenimiento, interacción, modernidad, 
personalización y riesgo percibido de los MS pueden estar afectando al CBBE en la industria de las aerolíneas. Y por último, Stojanovic et al. (2018) plantean un modelo en el que se analiza si la intensidad de uso de los MS por parte del turista acaba afectando a la formación del CBDBE (Consumer Based Destination Brand Equity). A pesar de estas notables aportaciones, hasta la fecha no se ha analizado si la exposición a las MS propias del destino, en las que se muestran contenidos de éste en forma de imágenes, videos, o comentarios de otros turistas, son capaces de influir en la formación del CBDBE del turista potencial.

Tomando en consideración las investigaciones anteriores, el objeto del presente trabajo consiste en avanzar en la literatura existente acerca de la influencia de los MS en la formación del capital de marca de un destino turístico. Concretamente los objetivos de este trabajo son: 1) proponer y validar un modelo de CBBE de un destino turístico, generado a partir de experiencias turísticas previas a la visita del destino, vividas a través de contenidos sobre el destino en MS; y 2) analizar las relaciones entre las distintas dimensiones que constituyen el CBBE de un destino turístico. Para alcanzar los anteriores objetivos, se plantea un estudio empírico, en el que se proporciona a los participantes una experiencia con un destino turístico a través de MS.

Alcanzar estos objetivos contribuye a avanzar en el conocimiento de la formación del capital de marca de un destino en la era de los MS (Stojanovic et al., 2018), así como la capacidad de los MS de proveer experiencias turísticas (Neuhofer et al., 2014; Sánchez Jiménez et al., 2020; Sigala, 2016). Ello va a permitir identificar de forma novedosa para la literatura, si la exposición a determinados contenidos sobre un destino turístico a través de MS, puede influir en los participantes de esta experiencia, permitiendo a éstos alcanzar un mayor conocimiento acerca del destino, una adecuada percepción de su imagen, calidad y valor percibido, lo que en consecuencia se traduce en una mayor intención de visitarlo o recomendarlo.

Para alcanzar estos objetivos, se diseñó un estudio empírico cuantitativo en el que los participantes estarían expuestos a información de un destino turístico a través de MS, siendo éste poco conocido por los participantes. Una vez expuestos a esta información, los participantes respondieron a un cuestionario que medía las distintas dimensiones que integran el CBBE del destino. El desarrollo de este trabajo de campo requería contar con un destino turístico que (a) utilizase los MS para dar a conocer el destino a turistas potenciales y (b) que fuese poco conocido, de forma que permita identificar una muestra de participantes que no cuente con conocimientos, ni experiencias previas en dicho destino. Una revisión de los destinos turísticos que utilizan los MS y que son menos conocidos por el público, llevó a identificar a Goa (https://goa-tourism.com) como el destino turístico idóneo para esta investigación.

El presente documento se estructura de la siguiente forma. En la primera parte, se lleva a cabo una revisión de la literatura turística en la que se presenta el post-turismo, sus implicaciones en la formación del CBBE a través de los MS, así como el modelo CBDBE a partir de experiencias turísticas vividas en MS que se plantea en este trabajo. El documento continúa con el estudio empírico y con la presentación de los resultados alcanzados. Y finalmente, se proponen las conclusiones del trabajo, sus implicaciones prácticas, sus limitaciones, así como las futuras líneas de investigación que se derivan de éstas. 


\section{REVISIÓN DE LA LITERATURA}

\subsection{El post-turismo a través de los medios sociales}

El término post-turismo fue acuñado por Maxine Feifer (1985) en su libro Going Places: The ways of the tourist from Imperial Rome to the present day. El concepto de post-turismo se estableció en respuesta a las nuevas actitudes y preferencias que estaban desarrollando los turistas del post-modernismo o post-turistas, turistas muy familiarizados y sensibles a las TICs, con un papel activo en la creación de las experiencias turísticas, con un nivel de ingresos y educativo superior, y con una mayor disponibilidad de tiempo libre (Dujmović y Vitasović, 2015).

El post-turismo se caracteriza por la posibilidad de vivir experiencias turísticas típicas sin "salir de casa" (Urry, 1988). Este tipo de experiencias son posibles gracias a la mediación y al desarrollo, que han sufrido medios como la televisión o plataformas de Internet (Jansson, 2018).

Autores como Feifer (1985) o Munt (1994) entienden por post-turismo un nuevo modo de viajar, uno en el que el viajero, un consumidor occidental de clase media, pretende distinguirse del turismo de masas. Esta visión del post-turista, cómo un individuo activo, creativo y vinculado con las nuevas tecnologías (Dujmović y Vitasović, 2015), no como un simple consumidor pasivo de productos turísticos, va muy al hilo con el concepto de "Clase Turística Creativa" (Florida, 2002), turistas cuyas experiencias son mediadas por las TICS (Gretzel y Jamal, 2009; Tussyadiah y Fesenmaier, 2009). Esta situación es la que Lash y Urry (1994) denominaron el "fin del turismo" o des-diferenciación, según la cual los límites de lo que es considerado tradicionalmente turismo y lo que no (perteneciente al ámbito de lo ordinario, de la rutina diaria), se estaban viendo desdibujados o difuminados, por la posibilidad de vivir durante nuestro día a día experiencias turísticas virtuales a través de medios y del consumo visual. Si anteriormente experiencias como la contemplación de lugares lejanos o la participación en otras culturas, estaban circunscritas a asumir un desplazamiento físico, actualmente son accesibles en diversos contextos de la vida cotidiana, a través de experiencias simuladas (Dujmović y Vitasović, 2015; Gretzel y Jamal, 2009). En consecuencia, "las personas son turistas la mayor parte del tiempo, ya sea porque se están moviendo literalmente, o sólo porque experimentan movilidad simulada a través de la increíble fluidez de múltiples señales e imágenes electrónicas" (Urry, 1990, p. 148).

Los avances tecnológicos han provocado profundos cambios en la sociedad y en la economía en general, incluidos sectores como el turístico (Cho et al., 2002; Gretzel et al., 2006). Como consecuencia de estos continuos avances en materia tecnológica, el turismo necesita de una constante reorientación y redefinición de sí mismo (Egger y Buhalis, 2008). De ahí que uno de los pilares en los que se sustenta el post-turismo sea la tecnología (Danilo Bezerra et al., 2012). Dentro de los avances tecnológicos basados en el uso intensivo de Internet, cabe destacar la importancia adquirida por los MS en el ámbito del turismo, estas plataformas han revolucionado la forma en la que los distintos stakeholders acceden, crean o comparen la información, interactúan entre sí, así como su capacidad de propiciar experiencias turísticas (Sigala, 2016). Los MS se han convertido en importantes herramientas de marketing a través de las cuáles los destinos, son capaces de alcanzar ventajas competitivas y de mantenerlas a lo largo del tiempo (Királ'ová y Pavlíčeka, 2015; Pike y Page, 2014). 
Hoy en día, todavía no existe una definición generalizada de MS, fruto del constante proceso de cambio, expansión, de sus usos y aplicaciones (Zeng y Gerritsen, 2014). Si bien, puede considerarse la propuesta de Chan y Guillet (2011, p.347), que definen los MS como "un grupo de aplicaciones basadas en Internet que existen en la plataforma Web 2.0 y que permiten a los usuarios de Internet de todo el mundo interactuar, comunicarse y compartir ideas, contenidos, pensamientos, experiencias, perspectivas, información y relaciones".

Más allá de las implicaciones en la promoción del destino, en la interacción del turista con el destino (Zeng y Gerritsen, 2014), o en la consecución de ventajas competitivas (Királ'ová y Pavlíčeka, 2015; Pike y Page, 2014), los MS son capaces de proveer experiencias turísticas previas a la visita del destino a través de los contenidos que son publicados en ellos (Gretzel y Jamal, 2009; Tussyadiah y Fesenmaier, 2009).

A la hora de crear un entorno simulado capaz de proporcionar experiencias realistas, la literatura destaca los elementos visuales y sonoros como dos de los más importantes (Gutiérrez et al., 2008; Tsingos et al., 2004). El contenido visual juega un papel muy importante a la hora de crear y comunicar con éxito la imagen de un destino (Cho et al., 2002). Tal y como apuntaba Urry (1990) con el concepto de "tourist gaze", la percepción visual es la base de la experiencia turística.

Las experiencias constituyen la esencia misma del turismo (Neuhofer et al., 2014), por ello, cuando los turistas están inmersos en la búsqueda de información acerca de un destino, no sólo desean conocer sus características puramente físicas y tangibles, sino que también desean en cierto modo experimentarlas (Cho et al., 2002). De forma que el

turista, tanto si está buscando activamente información a través de MS, o si por el contrario está siendo expuesto de forma pasiva a información visual de carácter turístico, puede verse implicado en una experiencia turística simulada (Choi, 2014). Gracias a las experiencias turísticas compartidas en MS, a través de videos o imágenes, los turistas potenciales pueden experimentar de forma remota el viaje (Tussyadiah y Fesenmaier, 2009).

A pesar de las implicaciones que puede traer consigo el uso de las TICs y en particular los MS, como medios válidos para generar experiencias turísticas, es un tema aún poco explorado en la literatura (Neuhofer et al., 2014; Sigala, 2016). Existen trabajos como los de Gertzel y Jamal (2009) o Tussyadiah y Fesenmaier (2009), donde se pone de manifiesto cómo los contenidos compartidos en MS son capaces de generar experiencias turísticas en los usuarios. Sin embargo, hasta el momento no se ha analizado el efecto que ejercen las experiencias turísticas generadas mediante contenidos compartidos en MS, en variables clave para la competitividad de los destinos turísticos como es el CBDBE.

\subsection{El CBDBE a través de los medios sociales}

El capital de marca ha sido considerado por la literatura un concepto central en la gestión de la marca (Aaker, 1996b; Keller, 1993; Stojanovic et al., 2018). El capital de marca es un término utilizado para representar el rendimiento de una marca, esto se puede medir ciñéndose a lo puramente contable o bien, mediante el CBBE, termino creado por Aaker (1991, 1996a) y Keller $(1993,2003)$. El CBBE posee un potencial clave para evaluar la efectividad de las acciones de marketing de las marcas, como indicador de posibles desempeños futuros (Aaker, 1996a). Keller (1993, p. 2), conceptualizó el CBBE como "el efecto diferencial del conocimiento de marca de un cliente, en respuesta al marketing de la marca". 
Trabajos como los de Konecnik y Gartner (2007), fueron los primeros en cuestionarse la aplicabilidad del concepto de CBBE, tradicionalmente desarrollado para marcas de productos, a productos turísticos. El CBBE ha sido aplicado y probado en contextos turísticos de lo más variados, entre éstos se encuentran: destinos (Frías-Jamilena et al., 2018; San Martín et al., 2018), hoteles (Kayaman y Arasli, 2007; Kim et al., 2008), restaurantes (Kim y Kim, 2005) o aerolíneas (Sarker et al., 2019; Seo y Park, 2018).

Sin embargo, la formación del CBDBE en un contexto de MS, aún permanece poco estudiado, tan solo se encuentran trabajos como el de Stojanovic et al. (2018), en el que se demuestra que la intensidad de uso de los MS por parte de los turistas, es una variable que influye en la formación del CBDBE. Si bien, partiendo de la anterior evidencia empírica, hasta la fecha no se ha analizado si las experiencias turísticas generadas a través de MS influyen en la formación del CBDBE.

Para avanzar en este ámbito de estudio, es necesario identificar y definir cuáles son las dimensiones que constituyen el modelo de CBDBE en un contexto de experiencias turísticas vividas en MS. La mayoría de los trabajos consideran como dimensiones del CBDBE: (a) la lealtad de marca, (b) la imagen de marca, (c) la calidad de marca, (d) el conocimiento de marca (Im et al., 2012; Pike et al., 2010; Zavattaro et al., 2015). Otros autores han incorporado a sus investigaciones una quinta dimensión: el valor percibido de marca (Bianchi et al., 2014; Boo et al., 2009; Kaushal et al., 2018; Kotsi et al., 2018).

\subsubsection{Lealtad actitudinal hacia la marca del destino}

Aaker (1991, p. 39) define la lealtad hacia la marca como "el apego que un cliente tiene hacia la marca". La literatura sugiere que el constructo lealtad está formado por dos dimensiones, una conductual o comportamental y otra actitudinal (Jones y Taylor, 2007; Li y Petrick, 2008). La dimensión conductual aplicada al contexto turístico hace referencia a la frecuencia en la repetición de visita y la actitudinal, a la intención de visitar o de recomendar el destino (Bianchi et al., 2014). Este estudio se centra exclusivamente en la dimensión actitudinal de la lealtad, dimensión considerada por la literatura como una buena medida de la lealtad hacia el destino (Bianchi et al., 2014) ya que, refleja las percepciones de los consumidores de acuerdo con la teoría del CBBE (Im et al., 2012).

La lealtad de un consumidor hacia la marca es clave en el constructo capital de marca. Se trata de una de las principales fuentes para crear valor de marca basadas en el cliente (Aaker, 1991; Keller, 2003).

\subsubsection{Imagen de marca del destino y su relación con la lealtad actitudinal hacia el destino}

Para Baloglu y McCleary (1999, p. 870), la imagen de un destino es "un constructo actitudinal, que consiste en la representación mental de un individuo de conocimientos (creencias), sentimientos e impresiones globales sobre un objeto o destino".

En la literatura existe cierto consenso con relación a que la imagen es una de las dimensiones más importantes del CBBE (Boo et al., 2009; Konecnik y Gartner, 2007). La imagen del destino es capaz de influir en la lealtad del turista hacia el destino (Bianchi et al., 2014; Ghafari et al., 2017; Im et al., 2012; Kaushal et al., 2018; Kim y Lee, 2018; Kotsi et al., 2018; Pike y Bianchi, 2016; Tran et al., 2018; Yang et al., 2015). Stojanovic et al. (2018) también plantearon en su modelo de MS y CBDBE, que la imagen que tiene un turista acerca de un 
destino, afecta a su intención de recomendarlo a otros tanto en un medio offline como online. Como apuntaban Llodra-Riera et al. (2015a, p. 474): "la imagen del destino, no sólo es esencial para atraer a nuevos visitantes, sino para fomentar la lealtad entre aquellos que ya lo han visitado". Siguiendo estos resultados, se plantea conocer si la imagen de marca influye en la lealtad actitudinal cuando la experiencia turística previa es generada a través de MS, mediante la siguiente hipótesis:

H1: La imagen de marca del destino a partir de la experiencia turística del individuo en MS, ejerce una influencia significativa positiva sobre la lealtad actitudinal hacia la marca del destino.

\subsubsection{Calidad de marca del destino y su relación con la lealtad actitudinal hacia el destino}

Keller (2003, p. 238) define la calidad percibida como "la percepción de calidad global o de superioridad de un producto o servicio, en relación con las diferentes alternativas y con respecto a su finalidad prevista". Por lo tanto, la calidad de marca de un destino turístico hace referencia a la percepción de calidad, relativa tanto a las instalaciones o servicios que ofrece, como a los demás aspectos no físicos que conforman dicho destino (Pike y Bianchi, 2016).

Autores como Aaker (1996a), Keller (2003) y Lassar et al. (1995) consideran la calidad de marca como una de las dimensiones clave del CBBE, en el sentido de que aporta razones a los consumidores para decantarse por una determinada marca y no por otra, o como una potente herramienta de diferenciación ante los competidores (Aaker, 1991; Im et al., 2012).

La calidad percibida de marca, es considerada por varios autores como un antecedente directo de la lealtad del consumidor hacia la marca en un contexto turístico (Bianchi y Pike, 2011; Bianchi et al., 2014; Chen y Chen, 2010; Kaushal et al., 2018; Kim y Lee, 2018; Kotsi et al., 2018; Pike et al., 2010; Tran et al., 2018; Yang et al., 2015), relación incluso planteada y confirmada en un entorno de MS (Stojanovic et al., 2018). En base a lo anterior, se propone determinar si dicha relación también se mantiene cuando la experiencia turística previa es generada a través de los MS, a través de la siguiente hipótesis:

H2: La calidad de marca del destino a partir de la experiencia turística del individuo en MS, ejerce una influencia significativa positiva sobre la lealtad actitudinal hacia la marca del destino.

\subsubsection{Valor percibido de marca del destino y su relación con la lealtad actitudinal hacia el destino}

El valor percibido es un concepto complejo tanto a la hora de medirlo como de definirlo, debido a su carácter personal e idiosincrásico (Zeithaml, 1988). Zeithaml y Bitner (2000) definen el valor percibido de un servicio, como una valoración global de la utilidad de un servicio, basada en la percepción que tiene el consumidor sobre lo que recibe a un determinado precio. Autores como Boo et al. (2009) o Bianchi et al. (2014) consideran el valor percibido como una dimensión central del CBBE.

En la literatura turística se establece una relación positiva entre el valor percibido y la lealtad del consumidor hacia la marca (Bianchi et al., 2014; Boo et al., 2009; Ghafari et al., 2017; Kaushal et al., 2018; Kotsi et al., 2018; Pike y Bianchi, 2016). Stojanovic et al. (2018) demostraron que, en el contexto de los MS, el valor percibido de un destino por parte de los turistas acaba afectando a las recomendaciones que hacen a otros tanto en un medio offline 
como online. Considerando los anteriores resultados, se plantea conocer si éstos también tienen lugar cuando se trata de experiencias turísticas previas generadas a través de los MS, proponiendo la siguiente hipótesis:

H3: El valor percibido de marca del destino a partir de la experiencia turística del individuo en MS, ejerce una influencia significativa positiva sobre la lealtad actitudinal hacia la marca del destino.

\subsubsection{Conocimiento de marca del destino y su relación con el resto de dimensiones del CBDBE}

El conocimiento de marca de un destino se puede definir como la fuerza que tiene la conciencia de un destino en la mente de un individuo, ante una situación de viaje (Bianchi et al., 2014; Pike y Bianchi, 2016).

Resulta primordial que el destino sea conocido por el consumidor, para que este pueda ser considerado un potencial destino a la hora de su elección. El conocimiento conlleva que la imagen del destino exista en la mente de los turistas potenciales (Gartner, 1993). Para que un destino sea próspero es necesario, primero, lograr una conciencia de este por parte del turista $y$, segundo, que la imagen que éste transmita sea positiva (Konecnik y Gartner, 2007).

En la literatura encontramos investigaciones que sugieren que el conocimiento de marca generado en un contexto de MS, es un antecedente directo de la imagen de marca (Barreda 2014; Fortezza y Pencarelli, 2018; Llodra-Riera et al., 2015b; Stojanovic et al., 2018). En consecuencia, es de esperar que dicha relación se confirme en un contexto de experiencias turísticas previas en MS. Por tanto, se propone la siguiente hipótesis:

H4: El conocimiento de marca del destino a partir de la experiencia turística del individuo en MS, ejerce una influencia significativa positiva sobre la imagen de marca que tiene del destino.

En diversos trabajos que estudian el CBDBE, se ha planteado si el conocimiento de marca de un destino, podría estar afectando a la formación de la lealtad de este (Kotsi et al., 2018; Liu y Fang, 2018; Pike y Bianchi, 2016; Yang et al., 2015). La investigación de Stojanovic et al. (2018), confirma que el conocimiento de marca generado en MS, acaba afectando a la intención de recomendar online el destino. Teniendo en cuenta las evidencias anteriores, con este trabajo se pretende probar la relación que existe entre el conocimiento de marca y la lealtad actitudinal a partir de experiencias turísticas previas generadas en MS, y para ello se propone la siguiente hipótesis:

H5: El conocimiento de marca del destino a partir de la experiencia turística del individuo en MS, ejerce una influencia significativa positiva sobre la lealtad actitudinal hacia la marca del destino.

La relación entre conocimiento de marca y la calidad de esta ha sido previamente confirmada por la literatura (Kaushal et al., 2018; Oh, 2000; Schivinski y Dabrowski, 2015; Tran et al., 2018); también en un contexto de MS y de destino turístico (Fortezza y Pencarelli, 2018; Stojanovic et al., 2018). En este trabajo se plantea determinar el efecto del conocimiento sobre la calidad de marca, a partir de experiencias turísticas previas generadas a través

de MS. Por tanto, se plantea la siguiente hipótesis: 
H6: El conocimiento de marca del destino a partir de la experiencia turística del individuo en MS, ejerce una influencia significativa positiva sobre la percepción de calidad de marca que tiene del destino.

En la literatura turística encontramos investigaciones que sugieren que el conocimiento de marca, es un antecedente directo del valor percibido de marca (Ghafari et al., 2017; Tasci, 2016). Stojanovic et al. (2018) demostraron la relación existente entre estas dos dimensiones en un contexto turístico de MS. De forma similar, se propone analizar el efecto del conocimiento sobre el valor percibido, cuando el conocimiento procede de experiencias turísticas previas generadas en MS, lo que lleva a plantear la siguiente hipótesis:

H7: El conocimiento de marca del destino a partir de la experiencia turística del individuo en MS, ejerce una influencia significativa positiva sobre el valor percibido de la marca que tiene del destino.

En la figura 1 se muestra el modelo teórico de CBDBE planteado. Conviene aclarar, como así queda reflejado en las hipótesis, que en el modelo propuesto sólo se plantean efectos directos, no se contemplan efectos indirectos o mediadores de las variables imagen, calidad y valor percibido.

Figura 1. Modelo CBDBE propuesto

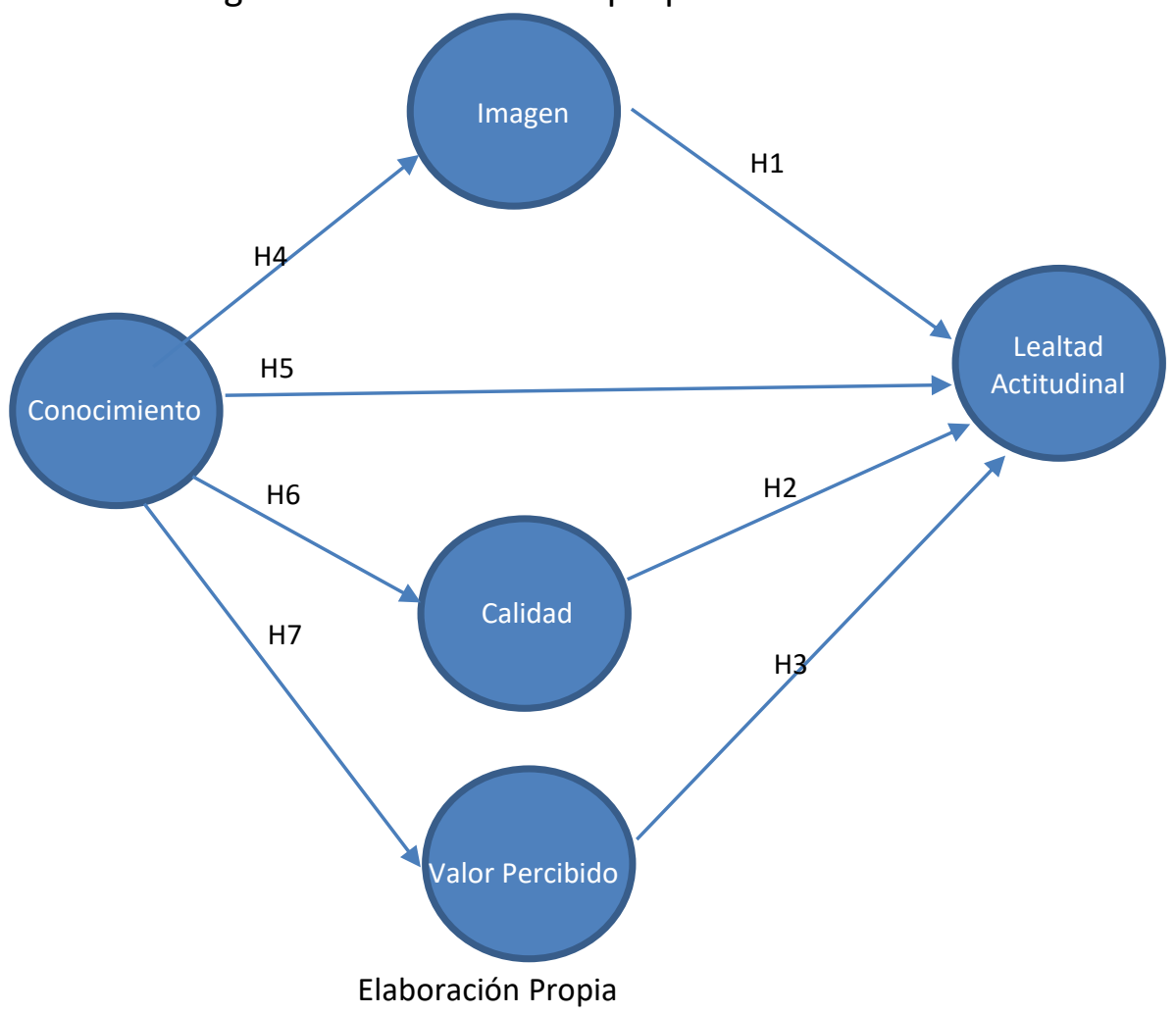




\section{METODOLOGÍA}

\subsection{Diseño de la muestra y recogida de datos}

Para contrastar las hipótesis que conforman el modelo propuesto, resultaba conveniente seleccionar un destino turístico que (a) utilizase los MS para darse a conocer el destino a turistas potenciales y (b) que fuese poco conocido por el público, de forma, que permitiese identificar una muestra de participantes para el estudio que no constase ni con conocimientos, ni con experiencias previas en dicho destino. Una revisión de los destinos turísticos que utilizan los MS y que son poco conocidos, llevó a identificar Goa (el estado más pequeño de la India en cuanto a extensión) como un buen candidato sobre el que desarrollar el trabajo de campo. Se llevó a cabo un estudio empírico asistido mediante cuestionario que se autoadministraba de forma personal en formato papel. La tabla 1 muestra la ficha técnica del estudio, donde se resumen los aspectos más importantes del trabajo de campo, así como otros aspectos metodológicos, que serán desarrollados a continuación.

La población del estudio estaba determinada por turistas potenciales que cumpliesen el requisito de no conocer, ni haber visitado con anterioridad el destino elegido para esta investigación, Goa. Este requisito podía cumplirse al seleccionar una muestra de participantes españoles, dado que según los últimos datos disponibles en la página web del Departamento de Turismo de Goa (2016), la cifra de españoles (junto con al menos otras diez nacionalidades de turistas), que visitaron Goa el año 2016 fue bastante reducida (un 5,87\% del total de visitantes de Goa para dicho año).

Resulta interesante para la investigación usar estos MS dado que los turistas suelen formar la imagen que tienen sobre los destinos turísticos, a partir información recabada en los perfiles oficiales del destino en MS (Molinillo et al., 2017). Además, por el perfil de la muestra, según datos ofrecidos por la agencia global We are social (2019), Facebook y Twitter son dos de los MS más utilizados por los españoles, incluso como fuente de información turística (Brogueira et al., 2017; Hosteltur, 2019; Molinillo et al., 2017; Sediyono y Nivak, 2014).

Aplicando un muestreo no probabilístico de conveniencia, finalmente, el público objetivo elegido para participar en esta investigación fueron estudiantes de grado de titulaciones vinculadas con el área de gestión, marketing y turismo, de una de las mayores y más prestigiosas universidades españolas (según los últimos datos del Ranking de Shanghái 2019, esta institución educativa se encuentra entre las 300 mejores universidades del mundo, y la tercera a nivel nacional). Esta elección se llevó a cabo por tres motivos: primero, porque es un colectivo muy conocedor y usuario habitual de MS antes del viaje (Nemec Rudež y Vodeb, 2015), tecnologías en las que se basa este estudio; segundo, porque son considerados por la literatura como turistas potenciales (Mura et al., 2017); y tercero, porque poseían en su mayoría nacionalidad española y, por tanto, se presupone que en su mayoría no han visitado Goa.

Previamente a la entrega del cuestionario, cada uno de los participantes fue expuesto durante 15 minutos a contenidos de Goa como destino turístico en MS. Concretamente, todos los participantes tuvieron acceso a los mismos contenidos expuestos en los perfiles sociales del Departamento de Turismo de Goa en Facebook (www.facebook.com/officialgoatourism) y Twitter (https://twitter.com/tourismgoa) en inglés, idioma que los estudiantes participantes dominaban. Los contenidos mostrados a través de estos perfiles de MS eran de tipo oficial, y eran gestionados por esta autoridad turística. Estos contenidos incluían imágenes y vídeos 
sobre recursos turísticos del destino, así como contenidos generados por turistas que ya lo habían visitado con anterioridad, en forma de comentarios, en respuesta a las publicaciones oficiales del destino. En las imágenes y videos podían apreciarse las principales atracciones turísticas de Goa: monumentos que han sido declarados patrimonio de la humanidad por la UNESCO (fortalezas, iglesias, catedrales...), la diversidad de culturas y de religiones que conviven en total armonía, sus playas (es su principal reclamo, posee 105 kilómetros de costa), y su variada oferta de actividades recreativas (actividades deportivas, festivales, ocio nocturno...) (Dwivedi et al., 2009). Estas características son reconocidas por la literatura como factores determinantes de la oferta de un destino (Beerli y Martín, 2004) y puede considerarse una información orientada a la captación de turistas potenciales.

Después de que los potenciales turistas visualizaran los perfiles sociales del Departamento de Turismo de Goa en Facebook y Twitter, estos tuvieron 10 minutos para completar el cuestionario. En total se realizaron 177 encuestas, de las cuáles finalmente sólo fueron válidas 170 , siete de los cuestionarios fueron eliminados al encontrarse incompletos. Con relación al perfil sociodemográfico de la muestra el 85,3\% tenía entre 20 y 25 años, eran mayoritariamente mujeres $(65,9 \%)$, y con un nivel de ingresos familiares que oscilaban entre los 600-1800 euros/mes (52,4\%). Este perfil resulta coherente con el obtenido en otros estudios llevados a cabo con muestras de estudiantes de grado españoles (Abdelmaaboud et al., 2020, Rejón et al., 2020).

Tabla 1. Ficha técnica del estudio

\begin{tabular}{|l|l|}
\hline Población & $\begin{array}{l}\text { Turistas potenciales de Goa, sin conocimientos previos sobre el } \\
\text { mismo }\end{array}$ \\
\hline Tipo de muestreo & No probabilístico. Conveniencia \\
\hline Tipo de encuesta & Autoadministrada de forma personal en formato papel \\
\hline Duración aproximada de la encuesta & Visualización página Facebook/Twitter de Goa: 15 min \\
\cline { 2 - 2 } & Completar cuestionario: 10 min \\
\hline Tamaño muestral válido & 170 \\
\hline Error muestral* & $7,5 \%$ \\
\hline Tratamiento de la información & Partial Least Squares (PLS) \\
\hline Nivel de confianza & $95 \%$ \\
\hline $\begin{array}{l}* \\
\text { Para la estimación de una proporción, donde } \mathrm{P}=\mathrm{Q}=0,5 \text { y } 95 \% \text { de intervalo de confianza, suponiendo muestreo }\end{array}$ \\
\hline
\end{tabular}

Elaboración Propia

\subsection{Escalas de medición}

Para analizar cada una de las dimensiones del CBDBE se emplearon escalas que previamente habían sido validadas por la literatura. En total se emplearon 15 ítems, y cada uno de ellos fue medido a través de una escala tipo Likert de 7 puntos. Todos los ítems empleados, fueron adaptados al contexto del estudio: Goa como destino, y a los contenidos expuestos de este en los dos MS oficiales.

Para medir el conocimiento de marca del destino, se utilizaron 4 ítems basados en los trabajos de Bianchi et al. (2014), Boo et al. (2009) y Konecnik y Gartner (2007). Para la imagen de marca del destino 2 ítems a partir de Baloglu y McCleary (1999), Frías et al. (2008), Lin et al. (2007) y Rodríguez-Molina et al. (2013). La calidad de marca del destino se midió a través de 3 ítems procedentes de Aaker (1991), Boo et al. (2009), Lassar et al. (1995) y Sweeney y 
Soutar (2001). La dimensión valor percibido de marca del destino se midió a través de 3 ítems basados en Bianchi et al. (2014) y Boo et al. (2009). Y, por último, para la lealtad actitudinal hacia la marca del destino, se utilizaron 3 ítems propuestos por Bianchi et al. (2014), Boo et al. (2009), Chi y Qu (2008) y Konecnik y Gartner (2007) (véase Anexo 1).

\subsection{Metodología de análisis de datos}

Las relaciones propuestas en el modelo teórico fueron estimadas utilizando un modelo de ecuaciones estructurales, mediante la técnica basada en varianzas Partial Least Squares (PLS), más conocida como PLS-SEM, con el software SmartPLS 3. 0 (Ringle et al., 2015). Se utilizó la técnica de PLS-SEM para la validación del modelo, dado que dicha técnica no necesita de unos supuestos mínimos sobre el tamaño de la muestra o la distribución de los datos, entre otras ventajas (Chin et al., 2003); además su uso está muy generalizado entre las investigaciones de marketing (Hair et al, 2012).

La evaluación de los modelos a través de la técnica PLS-SEM, es un proceso que implica dos etapas. En la primera de ellas se evalúa el modelo de medida, y se analiza la fiabilidad y la validez de los constructos; y en la segunda etapa, el modelo estructural o lo que es lo mismo, las relaciones entre las variables latentes, analizando aspectos como la relevancia predictiva o la significatividad de las relaciones estructurales. PLS-SEM estima la significatividad de los parámetros utilizando un método de remuestreo llamado bootstrapping introducida por Efron (1979) (Vinzi et al., 2010). Esta técnica consiste en extraer una serie de muestras con reemplazo de los datos originales, lo que permite hacer inferencias sobre el comportamiento de las muestras al ser extraídas de una población (Cordeiro et al., 2010). Se deben extraer como mínimo 5.000 submuestras (Hair et al, 2012), sólo en el caso de que el tamaño muestral original sea superior a ese número, el número de submuestras será superior. Una vez extraídas las submuestras, el modelo se estima para esas $\mathrm{N}$ submuestras, obteniéndose tantas estimaciones de cada uno de los parámetros del modelo como submuestras existan; además, se obtienen las estimaciones del estadístico $t$, que nos ayuda a valorar la significatividad de los parámetros estimados del modelo (Manzano, 2016).

\section{RESULTADOS}

En relación con el modelo de medida, los resultados provistos por PLS (Tabla 2) indican que se alcanzan valores recomendados por la literatura tanto en validez convergente como en fiabilidad. Todas las cargas son significativamente distintas de cero, superiores a 0,60 (Bagozzi y Yi, 1988), y las varianzas extraídas promedio (AVE) también superan el límite establecido de 0,50 (Fornell y Larcker, 1981). En cuanto a la fiabilidad, la fiabilidad compuesta (CR) y los $\alpha$ de Cronbach superan el umbral de 0,70. La existencia de validez discriminante ha sido probada a través del criterio de Fornell-Larcker (1981) y del ratio HT/MT de Henseler et al. (2014) para cada par de variables que debe ser menor a 0,9 (Gold et al., 2001) (Tabla 3). 
Tabla 2. Fiabilidad y validez convergente del instrumento de medida

\begin{tabular}{|c|c|c|c|c|c|c|}
\hline & Indicador & Carga & Valor $\mathbf{t}$ & $\begin{array}{c}\text { Alpha } \\
\text { cronbach }\end{array}$ & CR & AVE \\
\hline \multirow[t]{4}{*}{ Conocimiento } & AWA1 & 0,668 & 9,853 & \multirow{4}{*}{0,717} & \multirow{4}{*}{0,820} & \multirow{4}{*}{0,534} \\
\hline & AWA2 & 0,749 & 21,118 & & & \\
\hline & AWA3 & 0,804 & 17,460 & & & \\
\hline & AWA4 & 0,693 & 11,715 & & & \\
\hline \multirow[t]{2}{*}{ Imagen } & IG1 & 0,975 & 158,828 & \multirow{2}{*}{0,950} & \multirow{2}{*}{0,976} & \multirow{2}{*}{0,952} \\
\hline & IG2 & 0,977 & 179,402 & & & \\
\hline \multirow{3}{*}{$\begin{array}{l}\text { Lealtad } \\
\text { actitudinal }\end{array}$} & LOY1 & 0,856 & 32,684 & \multirow{3}{*}{0,755} & \multirow{3}{*}{0,859} & \multirow{3}{*}{0,671} \\
\hline & LOY2 & 0,854 & 38,640 & & & \\
\hline & LOY3 & 0,741 & 12,976 & & & \\
\hline \multirow[t]{3}{*}{ Calidad } & QUA1 & 0,858 & 27,818 & \multirow{3}{*}{0,720} & \multirow{3}{*}{0,845} & \multirow{3}{*}{0,647} \\
\hline & QUA2 & 0,856 & 27,844 & & & \\
\hline & QUA3 & 0,686 & 10,622 & & & \\
\hline \multirow[t]{3}{*}{ V Percibido } & VAL1 & 0,778 & 20,112 & \multirow{3}{*}{0,766} & \multirow{3}{*}{0,865} & \multirow{3}{*}{0,681} \\
\hline & VAL2 & 0,824 & 20,895 & & & \\
\hline & VAL3 & 0,872 & 32,206 & & & \\
\hline
\end{tabular}

Elaboración Propia

Tabla 3. Validez discriminante del instrumento de medida

\begin{tabular}{|l|c|c|c|c|c|}
\hline & Conocimiento & Imagen & $\begin{array}{c}\text { Lealtad } \\
\text { actitudinal }\end{array}$ & V Percibido & Calidad \\
\hline Conocimiento & 0,730 & 0,328 & 0,634 & 0,491 & 0,574 \\
\hline Imagen & 0,302 & 0,976 & 0,452 & 0,267 & 0,527 \\
\hline $\begin{array}{l}\text { Lealtad } \\
\text { actitudinal }\end{array}$ & 0,493 & 0,385 & 0,819 & 0,597 & 0,640 \\
\hline V Percibido & 0,372 & 0,229 & 0,463 & 0,826 & 0,547 \\
\hline Calidad & 0,439 & 0,432 & 0,490 & 0,411 & 0,804 \\
\hline
\end{tabular}

Nota: Valores en la diagonal: raíces cuadradas de los AVE; Debajo de la diagonal: correlaciones entre los factores; Sobre la diagonal: ratio HTMT

Elaboración Propia

Una vez evaluado el modelo de medida, el siguiente paso fue analizar la relevancia predictiva del modelo y la significatividad de las relaciones estructurales a través de la técnica de bootstrapping, empleando para ello un número de submuestras igual a 5000, y un nivel de significación del 5\% (Hair et al., 2017). Como se muestra en la tabla 4, la relevancia predictiva del modelo, medida a través del Q2 de Stone-Geisser (Stone, 1974; Geisser, 1975) es adecuada (Q2> 0); así como la varianza explicada (R2) de los constructos latentes es débil (Hair et al., 2017), aunque dentro de los valores recomendados (entre 0 y 1). Dicha tabla también recoge los resultados del modelo estructural, en ella se puede ver como los coeficientes han resultado positivos y significativamente distintos de cero, por lo que podemos concluir en relación a las hipótesis consideradas:

La hipótesis 1, hace referencia a que la imagen de marca del destino a partir de la experiencia turística del individuo en MS, ejerce una influencia significativa positiva sobre la lealtad actitudinal hacia la marca del destino. En base a los resultados del análisis, dicha 
relación resulta positiva y significativa ( $\beta 1$ imagen-lealtad actitudinal: 0,$161 ; p<0,05$ ) por lo tanto, recibe apoyo empírico.

La hipótesis 2 que recoge que la calidad de marca del destino a partir de la experiencia turística del individuo en MS, ejerce una influencia significativa positiva sobre la lealtad actitudinal hacia la marca del destino, también recibe apoyo empírico ( $\beta 2$ calidad-lealtad actitudinal: 0,$205 ; p<0,05)$.

La hipótesis 3, establece que el valor percibido de marca del destino a partir de la experiencia turística del individuo en MS, ejerce una influencia significativa positiva sobre la lealtad actitudinal hacia la marca del destino. El parámetro estimado resultante es positivo y significativo, lo que permite apoyar empíricamente dicha hipótesis ( $\beta 3$ valor percibido-lealtad actitudinal: 0,244; $p<0,05)$.

La hipótesis 4, hace referencia a que la dimensión conocimiento de marca del destino a partir de la experiencia turística del individuo en MS, ejerce una influencia significativa positiva sobre la imagen de marca del destino. Los resultados muestran que dicha relación es positiva y significativa ( $\beta 4$ conocimiento-imagen: 0,$302 ; p<0,05$ ), por lo que se concluye también su apoyo empírico.

La hipótesis 5 propone que el conocimiento de marca del destino a partir de la experiencia turística del individuo en MS, ejerce una influencia significativa positiva sobre la lealtad actitudinal hacia la marca del destino. Los resultados obtenidos permiten dar apoyo empírico a dicha hipótesis, dado que el coeficiente correspondiente resultó positivo y significativo ( $\beta 5$ conocimiento- lealtad actitudinal: 0,$264 ; p<0,05$ ).

La hipótesis 6, también recibe apoyo empírico. Esta hipótesis establece que el conocimiento de marca del destino a partir de la experiencia turística del individuo en MS, ejerce una influencia significativa positiva sobre la percepción de calidad de marca del destino. El parámetro estimado resultó positivo y significativo ( $\beta 6$ conocimiento-calidad: 0,439 ; $p<0,05)$.

Finalmente, la hipótesis 7, que plantea que el conocimiento de marca del destino a partir de la experiencia turística del individuo en MS, ejerce una influencia significativa positiva sobre el valor percibido de marca del destino. Esta hipótesis encuentra apoyo empírico al resultar significativa ( $\beta 7$ conocimiento-valor percibido: 0,$372 ; p<0,05$ ).

Tabla 4. Contraste de hipótesis

\begin{tabular}{|c|c|c|c|c|}
\hline & $\begin{array}{c}\text { Beta } \\
\text { estandarizado }\end{array}$ & Valor $\mathbf{t}$ & P Valor & $\begin{array}{c}\text { Recibe apoyo } \\
\text { empírico }\end{array}$ \\
\hline H1: Imagen -> Lealtad actitudinal & 0,161 & 2,415 & 0,016 & Sí \\
\hline H2: Calidad-> Lealtad actitudinal & 0,205 & 2,656 & 0,008 & Sí \\
\hline H3: Valor percibido-> Lealtad actitudinal & 0,244 & 3,246 & 0,001 & Sí \\
\hline H4: Conocimiento-> Imagen & 0,302 & 5,132 & 0,000 & Sí \\
\hline H5: Conocimiento-> Lealtad actitudinal & 0,264 & 3,682 & 0,000 & Sí \\
\hline H6: Conocimiento -> Calidad & 0,439 & 7,403 & 0,000 & Sí \\
\hline H7: Conocimiento-> V Percibido & 0,372 & 4,982 & 0,000 & Sí \\
\hline
\end{tabular}

Elaboración Propia 


\section{DISCUSIÓN DE LOS RESULTADOS, CONCLUSIONES, IMPLICACIONES PRÁCTICAS Y LIMITACIONES}

Una variable clave para la competitividad de un destino turístico es el capital de marca (Boo et al., 2009; Keller, 2003; Wong, 2018). Para mejorar ese capital de marca, resulta interesante considerar las posibilidades que ofrecen las TICs como son los MS (Avila Campoverde y Ugalde, 2020; Barreda, 2014; Királ'ová y Pavlíčeka, 2015). El sector ha manifestado el uso predominante qua hacen de los medios sociales para trasmitir información turística (Brogueira et al., 2017; Hosteltur, 2019; Molinillo et al., 2017; Sediyono y Nivak, 2014); esto puede explicarse porque los UGC (User Generated Content) o eWom (recomendaciones boca-oído en su versión online) que afloran en este medio, son considerados una fuente que goza de una gran confianza y credibilidad por parte de los usuarios de estos medios (Burgess et al., 2011; Litvin et al., 2008). A partir de lo cual, en este trabajo se destaca la capacidad de estos medios para generar una experiencia turística en el participante, y como esta contribuye a la formación del capital de marca del destino.

La literatura ha puesto de manifiesto la necesidad de un mayor número de investigaciones que profundicen en la formación del capital de marca de un destino en la era de los MS (Stojanovic et al., 2018), así como la capacidad de los MS de proveer experiencias turísticas (Neuhofer et al., 2014; Sánchez Jiménez et al., 2020; Sigala, 2016). De ahí que, en esta investigación, se haya propuesto y validado un modelo de formación del CBDBE en un contexto de MS. Concretamente, se ha analizado el efecto que tienen las experiencias turísticas previas a la visita del destino, mediante contenidos compartidos en MS, sobre el capital de marca de un destino; así como las distintas relaciones que se dan entre las dimensiones que conforman el CBDBE. Es decir, nuestra investigación ha permitido identificar de forma novedosa para la literatura, que la exposición a determinados contenidos sobre un destino turístico a través de MS, puede influir en los participantes de esta experiencia, permitiendo a éstos alcanzar un mayor conocimiento acerca del destino, así como una adecuada percepción de la imagen, calidad y valor percibido del mismo, lo que en consecuencia se traduce en una mayor intención de visitarlo/recomendarlo.

De esta investigación se derivan varias contribuciones interesantes para la literatura académica relativa a la formación del CBDBE en un contexto de MS. En primer lugar, se ha comprobado que efectivamente la formación del capital de marca de un destino se puede ver afectada por las experiencias turísticas generadas a través de MS, lo que ha permitido profundizar en la literatura que señala que los contenidos generados en MS son capaces de desencadenar en el turista la vivencia de experiencias turísticas previas (Gretzel y Jamal, 2009; Tussyadiah y Fesenmaier, 2009), en concreto, contenidos en forma de videos, imágenes y comentarios acerca de las principales atracciones turísticas de un destino. No obstante, con esta investigación se avanza un poco más al plantear que dichas experiencias previas con el destino a través de contenidos pueden estar afectando a las percepciones que tiene el turista acerca del capital de marca del destino, incluso antes de visitarlo. También se ha comprobado, que el conocimiento de marca del destino que tiene el individuo, generado a partir de la vivencia de experiencias turísticas a través de MS, acaba afectando al resto de dimensiones del capital de marca: imagen, lealtad actitudinal, calidad y valor percibido, resultados en línea con los obtenidos en trabajos previos como el de Stojanovic et al (2018). Y que la lealtad actitudinal hacia la marca del destino, es una dimensión dependiente del conocimiento, 
imagen, calidad y valor percibido de marca del destino, tal y como señalan investigaciones como las de Kotsi et al. (2018) o Pike y Bianchi (2016).

En segundo lugar, se refuerza el papel de las TICs en el contexto del post-turismo, uno de sus pilares fundamentales (Danilo Bezerra et al., 2012). Hasta la fecha son escasos los trabajos que tratan de analizar la influencia de los MS en la formación del capital de marca de un destino. Como excepción se encuentra el trabajo de Stojanovic et al. (2018), centrado en la intensidad de uso de los MS por parte del turista. Finalmente, se acentúa la capacidad que tienen los MS para que un destino adquiera ventajas competitivas, en nuestra investigación a través de una mejora del CBDBE. Ampliando de ese modo los resultados obtenidos en trabajos como los de Királová y Pavlíčeka (2015) o Pike y Page (2014), en los que se pone de manifiesto la importancia de los MS para que un destino adquiera ventajas competitivas.

\subsection{Implicaciones prácticas}

Los resultados de este trabajo pueden ser de interés para la gerencia de los destinos turísticos, dado que se refuerza la idea de la existencia de una relación entre el uso de los MS que hacen los turistas y la formación del capital de marca de un destino turístico (Stojanovic et al., 2018). De forma que la visita previa a un destino a través de contenidos publicados en MS en forma de imágenes, videos o comentarios de otros visitantes, sobre sus principales reclamos (playas, monumentos o actividades de ocio), contribuye a la formación del CBDBE entre los participantes en esta experiencia virtual.

La capacidad de las TICs como los MS de generar en el usuario experiencias turísticas previas sin necesidad de un desplazamiento físico, es una herramienta muy interesante para los destinos de cara a mejorar su accesibilidad, al permitir a los potenciales turistas alcanzar sus propias experiencias con el destino durante el desempeño de su día a día, como postula el post-turismo.

Queda demostrado como el CBBE de un destino puede formarse a partir de experiencias simuladas a través de los MS, experiencias que pueden convertirse en una fuente de ventajas competitivas, a través de las cuáles las DMOs (Destination Markering Organizations) son capaces de añadir valor al destino, y diferenciarse de los competidores (Cho et al., 2002). Además, a la luz de las desafiantes circunstancias actuales generadas por la pandemia de COVID-19, es fundamental que se implementen estrategias para reactivar el sector e impulsar el CBDBE, una buena opción sería hacerlo a través de los MS, Facebook y Twitter. Además de ser un importante escaparate para la promoción de los productos turísticos, son plataformas que recopilan una gran cantidad de datos acerca de sus usuarios, lo que amplía las posibilidades para los profesionales del marketing turístico (Eyefortravel, 2017).

Sería interesante que los gerentes de los destinos tratasen de planificar, controlar, qué contenidos acerca de sus destinos son publicados en perfiles de MS, además de fomentar el consumo de información turística a través de estos. Estos contenidos en plataformas de MS, pueden traducirse en experiencias turísticas para los potenciales turistas, que acaban desencadenando en (1) un mayor conocimiento del destino, (2) una mejora en la calidad percibida, (3) una buena imagen del destino, (4) un alto valor percibido y finalmente (5), en una intención de visitar o recomendar el destino. 
Por último, el uso de los MS como medio a través del cual generar experiencias con el destino, constituye una herramienta muy poderosa y asequible para que los destinos puedan generar CBDBE entre turistas potenciales pertenecientes a distintos entornos geográficos.

\subsection{Limitaciones y futuras líneas de investigación}

A pesar de que este trabajo trae consigo interesantes evidencias relacionadas con la formación del CBDBE en un contexto de MS, hay que ser conscientes de las limitaciones que presenta, pudiendo éstas constituir futuras líneas de investigación. Primero, el modelo planteado es probado sólo en el destino de Goa, lugar con unas características muy concretas (destino exótico de sol y playa, y en un país como la India), por lo que la generalización de los resultados a otro tipo de destinos podría ser cuestionada. Futuras investigaciones podrían analizar si existen diferencias a la hora de formar el CBDBE del destino a través de experiencias en MS dependiendo de la localización geográfica del mismo, de su grado de especialidad turística, o de los MS elegidos para el estudio. Además, resultaría interesante analizar las diferencias en la formación del CBDBE cuando el turista potencial utiliza MS para buscar información turística, frente al uso de otras fuentes de información.

Segundo, limitaciones relacionadas con la muestra. Por un lado, el reducido tamaño muestral y por otro, la composición de la muestra. Al llevar a cabo el estudio empírico en España, se podría estar afectando a la generalización de los resultados ya que, en realidad, la población objeto de estudio son todos aquellos turistas potenciales de Goa a escala mundial que tienen acceso a los perfiles sociales del Departamento de Turismo de Goa. Investigaciones futuras podrían abrir la participación a todos los turistas potenciales con independencia de su nacionalidad.

\section{REFERENCIAS BIBLIOGRÁFICAS}

Aaker, D. A. (1991). Managing brand equity. New York: The Free Press.

Aaker, D. A. (1996a). Building strong brands. New York: The Free Press.

Aaker, D. A. (1996b). Measuring brand equity across products and markets. California management review, 38(3).

Abdelmaaboud, A. K., Peña, A. I. P., \& Mahrous, A. A. (2020). The influence of studentuniversity identification on student's advocacy intentions: the role of student satisfaction and student trust. Journal of Marketing for Higher Education, 1-23.

Avila Campoverde, F. y Ugalde, C. (2020). Instagram supera a Facebook y Twitter como la red social con mayor interacción para promocionar destinos turísticos en Ecuador. Investigaciones Turísticas, 19, 50-72.

Bagozzi, R. P., y Yi, Y. (1988). On the evaluation of structural equation models. Journal of the Academy of Marketing Science, 16(1), 74-94.

Baloglu, S., y McCleary, K. W. (1999). A model of destination image formation. Annals of Tourism Research, 26(4), 868-897.

Barreda, A. (2014). Creating brand equity when using travel-related online social network Web sites. Journal of Vacation Marketing, 20(4), 365-379.

Beerli, A., \& Martín, J. D. (2004). Factors influencing destination image. Annals of Tourism Research, 31(3), 657-681. 
Bianchi, C. y Pike, S. (2011), "Antecedents of destination brand loyalty for a long-haul market: Australia's destination loyalty among Chilean travelers". Journal of Travel \& Tourism Marketing, 28(7), 736-750.

Bianchi, C., Pike, S., y Lings, I. (2014). Investigating attitudes towards three South American destinations in an emerging long haul market using a model of consumer-based brand equity (CBBE). Tourism Management, 42, 215-223.

Boo, S., Busser, J., y Baloglu, S. (2009). A model of customer-based brand equity and its application to multiple destinations. Tourism Management, 30(2), 219-231.

Brogueira, G., Batista, F., \& Carvalho, J. P. (2017). A smart system for twitter corpus collection, management and visualization. International Journal of Technology and Human Interaction (IJTHI), 13(3), 13-32.

Bruhn, M., Schoenmueller, V., y Schäfer, D. B. (2012). Are social media replacing traditional media in terms of brand equity creation? Management Research Review, 35(9), 770790.

Burgess, S., Sellitto, C., Cox, C., \& Buultjens, J. (2011). Trust perceptions of online travel information by different content creators: Some social and legal implications. Information Systems Frontiers, 13(2), 221-235.

Chan, N. L., y Guillet, B. D. (2011). Investigation of social media marketing: how does the hotel industry in Hong Kong perform in marketing on social media websites? Journal of Travel \& Tourism Marketing, 28(4), 345-368.

Chen, C.F., y Chen, F.S. (2010) Experience quality, perceived value, satisfaction and behavioral intentions for heritage tourists. Tourism Management 31(1), 29-35

Chi, C. G.Q., y Qu, H. (2008). Examining the structural relationships of destination image, tourist satisfaction and destination loyalty: an integrated approach. TouriS Management, 29(4), 624- 636.

Chin, W. W., Marcolin, B. L., y Newsted, P. R. (2003). A partial least squares latent variable modeling approach for measuring interaction effects: Results from a Monte Carlo simulation study and an electronic-mail emotion/adoption study. Information systems research, 14(2), 189-217.

Cho, Y. H., Wang, Y., y Fesenmaier, D. R. (2002). Searching for experiences: The web-based virtual tour in tourism marketing. Journal of Travel \& Tourism Marketing, 12(4), 1-17.

Choi, Y. (2014). Online travel media and touristic experience: Examining the psychological effects of technology affordances. (Dissertation). The Pennsylvania State University. Pennsylvania

Cordeiro, C., Machás, A., \& Neves, M. M. (2010). A case study of a customer satisfaction problem: Bootstrap and imputation techniques. In Handbook of partial least squares (pp. 279-287). Springer, Berlin, Heidelberg.

Danilo Bezerra, É., Melo Silva Luft, M. C., y Rocha Dacorso, A. L. (2012). El turismo en la sociedad de la información. Un abordaje conceptual sobre el" post-turismo". Estudios y perspectivas en turismo, 21(5). 
Dujmović, M., y Vitasović, A. (2015). Postmodern Society and Tourism. Journal of Tourism and Hospitality Management, 3(9-10), 192-203.

Dwivedi, M., Yadav, A., \& Raghavjibhai Patel, V. (2009). The online destination image of Goa. Worldwide Hospitality and Tourism Themes, 1(1), 25-39.

Efron, B. (1979). Bootstrap methods: another look at the Jackknife. The Annals of Statistics, 7, $1-26$.

Egger, R., y Buhalis, D. (Eds.). (2011). Etourism case studies. Routledge.

Escalas, J. E. (2004). Imagine yourself in the product: Mental simulation, narrative transportation, and persuasion. Journal of advertising, 33(2), 37-48.

Eyefortravel (2017). The State of Data and Analytics in Travel Report 2017. Recuperado de https://www.reutersevents.com/travel/revenue-and-data-management/state-dataand-analytics-travel-report-2017

Feifer, M. (1985). Going places. The ways of the tourist from Imperial Rome to the present day. MacMillan London Limited.

Florida, R. (2002). The rise of the creative class and how it's transforming work, leisure, community and every- day life. New York: Basic Books.

Fornell, C., y Larcker, D. F. (1981). Evaluating structural equation models with unobservable variables and measurement error. Journal of Marketing Research, 39-50.

Fortezza, F., y Pencarelli, T. (2018). A comprehensive picture of the social media challenge for DMOs. Anatolia, 29(3), 456-467.

Frías, D.M., Rodríguez, M.A., y Castañeda, J.A. (2008). Internet vs. travel agencies on pre-visit destination image formation: An information processing view. Tourism Management, 29, 163-179.

Frías-Jamilena, D.M., Sabiote-Ortiz, A., Martín-Santana, J.D. y Beerli-Palacio, A. (2018). The effect of Cultural Intelligence on consumer-based destination brand equity. Annals of Tourism Research, 72, 22-36.

Gartner, W. C. (1993). Image formation process. Journal of Travel \& Tourism Marketing, 2(23), 191-216.

Geisser, S. (1975). The predictive sample reuse method with applications. Journal of the American Statistical Association, 70(350), 320-328.

Ghafari, M., Ranjbarian, B., y Fathi, S. (2017). Developing a brand equity model for tourism destination. International Journal of Business Innovation and Research, 12(4), 484-507.

Gold, A., Malhotra, A., y Segars, A. (2001). Knowledge management: An organizational capabilities perspective. Journal of Management Information Systems, 18(1), 185-214.

Government of Goa Department of Tourism Web Site (2016). Nationality. Recuperado de http://www.goatourism.gov.in/statistics/247

Gretzel, U., y Jamal, T. (2009). Conceptualizing the creative tourist class: Technology, mobility, and tourism experiences. Tourism Analysis, 14(4), 471-481. 
Gretzel, U., Fesenmaier, D. R., Formica, S., y O'Leary, J. T. (2006). Searching for the future: Challenges faced by destination marketing organizations. Journal of Travel Research, 45(2), 116-126.

Gutiérrez, M., Vexo, F., y Thalmann, D. (2008). Stepping into virtual reality. London: Springer.

Hair, J. F., Sarstedt, M., Ringle, C. M., \& Mena, J. A. (2012). An assessment of the use of partial least squares structural equation modeling in marketing research. Journal of the Academy of Marketing Science, 40, 414-433.

Hair, J.F., Hult, G.T.M., Ringle, C.M., y Sarstedt, M. (2017). A Primer on Partial Least Squares Structural Equation Modeling (PLS-SEM). Sage publications.

Henseler, J., Ringle, C. M., y Sarstedt, M. (2014). A new criterion for assessing discriminant validity in variance-based structural equation modeling. Journal of the Academy of Marketing Science, 43(1), 115-135.

Hosteltur (2019). Redes sociales preferidas por el turismo para el marketing digital. Recuperado de https://www.hosteltur.com/127669 redes-sociales-preferidas-por-elturismo-para-el-marketing-digital.html

Im, H. H., Kim, S. S., Elliot, S., y Han, H. (2012). Conceptualizing destination brand equity dimensions from a consumer-based brand equity perspective. Journal of Travel \& Tourism Marketing, 29(4), 385-403.

Jansson, A. (2018). Rethinking post-tourism in the age of social media. Annals of Tourism Research, 69, 101-110.

Jones, T., y Taylor, S. F. (2007). The conceptual domain of service loyalty: how many dimensions? Journal of Services Marketing, 21(1), 36-51.

Kaushal, V., Sharma, S., y Reddy, G. M. (2018). A structural analysis of destination brand equity in mountainous tourism destination in northern India. Tourism and Hospitality Research.

Kayaman, R., y Arasli, H. (2007). Customer based brand equity: evidence from the hotel industry. Managing Service Quality: An International Journal, 17(1), 92-109.

Keller, K. L. (1993). Conceptualizing, measuring, and managing customer-based brand equity. Journal of Marketing, 57(1), 1-22.

Keller, K. L. (2003). Strategic brand management: Building, measuring, and managing. Upper Saddle River, NJ: Prentice Hall.

Keller, K. L. (2016). Reflections on customer-based brand equity: perspectives, progress, and priorities. AMS review, 6(1-2), 1-16.

Kim, H. B., y Kim, W. G. (2005). The relationship between brand equity and firms' performance in luxury hotels and chain restaurants. Tourism Management, 26(4), 549-560.

Kim, A. J., y Ko, E. (2012). Do social media marketing activities enhance customer equity? An empirical study of luxury fashion brand. Journal of Business Research, 65(10), 14801486.

Kim, H. K., y Lee, T. (2018). Brand equity of a tourist destination. Sustainability, 10(2), 431. 
Kim, W. G., Jin-Sun, B., y Kim, H. J. (2008). Multidimensional customer-based brand equity and its consequences in midpriced hotels. Journal of Hospitality \& Tourism Research, 32(2), 235-254.

Királová, A., y Pavlíčeka, A. (2015). Development of social media strategies in tourism destination. Procedia-Social and Behavioral Sciences, 175, 358-366.

Konecnik, M., y Gartner, W. C. (2007). Customer-based brand equity for a destination. Annals of Tourism Research, 34(2), 400-421.

Kotsi, F., Pike, S., y Gottlieb, U. (2018). Consumer-based brand equity (CBBE) in the context of an international stopover destination: Perceptions of Dubai in France and Australia. Tourism Management, 69, 297-306.

Lash, S. M., Urry, S. L. J., y Urry, J. (1994). Economies of signs and space (Vol. 26). London: Sage publications.

Lassar, W., Mittal, B., y Sharma, A. (1995). Measuring customer-based brand equity. Journal of Consumer Marketing, 12(4), 11-19.

$\mathrm{Li}, \mathrm{X}$., y Petrick, J. F. (2008). Reexamining the dimensionality of brand loyalty: A case of the cruise industry. Journal of Travel \& Tourism Marketing, 25(1), 68-85.

Lin, C.H., Morais, D.B., Kerstetter, D.L., y Hou, J.S. (2007). Examining the role of cognitive and affective image in predicting choice across natural, developed, and theme-park destinations. Journal of Travel Research, 46, 183-194.

Litvin, S. W., Goldsmith, R. E., \& Pan, B. (2008). Electronic word-of-mouth in hospitality and tourism management. Tourism Management, 29(3), 458-468.

Liu, C. H., y Fang, Y. P. (2018). Conceptualizing, validating, and managing brand equity for tourist satisfaction. Journal of Hospitality \& Tourism Research, 42(6), 960-978.

Llodra-Riera, I., Martínez-Ruiz, M.P., Jiménez-Zarco, A. I., y Izquierdo-Yusta, A. (2015a). Assessing the influence of social media on tourists' motivations and image formation of a destination. International Journal of Quality and Service Sciences, 7(4), 458-482.

Llodra-Riera, I., Martínez-Ruiz, M.P., Jiménez-Zarco, A.I. y Izquierdo-Yusta, A. (2015b), “A multidimensional analysis of the information sources construct and its relevance for destination image formation", Tourism Management, 48, 319-328.

Marasco, A., Buonincontri, P., van Niekerk, M., Orlowski, M., y Okumus, F. (2018). Exploring the role of next-generation virtual technologies in destination marketing. Journal of Destination Marketing \& Management, 9, 138-148.

Manzano, J. A. (2016). Modelización estructural con PLS-SEM: Constructos de segundo orden. ADD.

Molinillo, S., Liébana-Cabanillas, F., \& Anaya-Sánchez, R. (2017). Destination image on the DMO's platforms: official website and social media. Tourism \& Management Studies, 13(3), 5-14.

Munt, I. (1994). The Other postmodern tourism: culture, travel and the new middle classes. Theory, Culture \& Society, 11(3), 101-123. 
Muñoz-Guarasa, M., y Moral-Pajares, E. (2019). La internacionalización de los servicios turísticos en Andalucía: características y factores determinantes. Estudios de Economía Aplicada, 37(1).

Mura, P., Tavakoli, R., \& Sharif, S. P. (2017). 'Authentic but not too much': exploring perceptions of authenticity of virtual tourism. Information Technology \& Tourism, 17(2), 145-159.

Nemec Rudež, H., \& Vodeb, K. (2015). Students' use of social media during the travel process. Tourism and hospitality management, 21(2), 179-190.

Neuhofer, B., Buhalis, D., y Ladkin, A. (2014). A typology of technology-enhanced tourism experiences. International Journal of Tourism Research, 16(4), 340-350.

Oh, H. (2000). The effect of brand class, brand awareness, and price on customer value and behavioral intentions. Journal of Hospitality \& Tourism Research, 24(2), 136-162.

Pike, S., y Page, S. J. (2014). Destination Marketing Organizations and destination marketing: A narrative analysis of the literature. Tourism Management, 41, 202-227.

Pike, S., y Bianchi, C. (2016). Destination brand equity for Australia: testing a model of CBBE in short-haul and long-haul markets. Journal of Hospitality \& Tourism Research, 40(1), 114-134.

Pike, S., Bianchi, C., Kerr, G., y Patti, C. (2010). Consumer-based brand equity for Australia as a long-haul tourism destination in an emerging market. International Marketing Review, 27(4), 434-449.

Rejón-Guardia, F., Polo-Peña, A. I., \& Maraver-Tarifa, G. (2020). The acceptance of a personal learning environment based on Google apps: The role of subjective norms and social image. Journal of Computing in Higher Education, 32(2), 203-233.

Ringle, C. M., Wende, S., y Becker, J. M. (2015). SmartPLS 3.0. Recuperado de http://www.smartpls.com . Hamburg, Alemania: Universidad de Hamburg.

Ritzer, G., y Liska, A. (2004). Complementary perspectives on contemporary tourism. Tourism: New directions and alternative tourism, 4, 65.

Rodríguez Molina, M. Á., Frías-Jamilena, D. M., y Castañeda-García, J. A. (2013). The moderating role of past experience in the formation of a tourist destination's image and in tourists' behavioural intentions. Current Issues in Tourism, 16(2), 107-127.

San Martín, H., Herrero, A., y García de los Salmones, M. d. M. (2018). An integrative model of destination brand equity and tourist satisfaction. Current Issues in Tourism, 1-22.

Sánchez Jiménez, M. Á., Fernández Alles, M. F. y Mier-Terán Franco, J. J. (2020). El uso y la importancia de las redes sociales en el sector hotelero desde la perspectiva de los responsables de su gestión. Investigaciones Turísticas, 20, 50-78.

Sarker, M. M., Mohd-Any, A. A., y Kamarulzaman, Y. (2019). Conceptualising consumer-based service brand equity (CBSBE) and direct service experience in the airline sector. Journal of Hospitality and Tourism Management, 38, 39-48.

Schivinski, B., y Dabrowski, D. (2015). The impact of brand communication on brand equity through Facebook. Journal of Research in Interactive Marketing, 9(1), 31-53. 
Sediyono, E., \& Nivak, C. (2014). Measuring the Performance of Ontological Based Information Retrieval from a Social Media. In 2014 European Modelling Symposium (pp. 354-359). IEEE.

Seo, E. J., y Park, J. W. (2018). A study on the effects of social media marketing activities on brand equity and customer response in the airline industry. Journal of Air Transport Management, 66, 36-41.

Sigala, M. (2016). Social media and the co-creation of tourism experiences. In The handbook of managing and marketing tourism experiences (pp. 85-111). Emerald Group Publishing Limited.

Stojanovic, I., Andreu, L., y Curras-Pérez, R. (2018). Effects of the intensity of use of social media on brand equity: An empirical study in a tourist destination. European Journal of Management and Business Economics, 27(1), 83-100.

Stone, M. (1974). Cross-validatory choice and assessment of statistical predictions. Journal of the Royal Statistical Society: Series B (Methodological), 36(2), 111-147

Sweeney, J., y Soutar, G. N. (2001). Consumer perceived value: the development of a multiple item scale. Journal of Retailing, 77(2), 203-220.

Tasci, A.D. (2016), "A critical review of consumer value and its complex relationships in the consumer-based brand equity network". Journal of Destination Marketing \& Management, 5(3), 171-191.

Tran, V. T., Nguyen, N. P., Tran, P. T. K., Tran, T. N., y Huynh, T. T. P. (2018). Brand equity in a tourism destination: a case study of domestic tourists in Hoi An city, Vietnam. Tourism Review.

Tsingos, N., Gallo, E., y Drettakis, G. (2004). Perceptual audio rendering of complex virtual environments. ACM Transactions on Graphics, 23(3), 249-258.

Tussyadiah, I. P., y Fesenmaier, D. R. (2009). Mediating tourist experiences: Access to places via shared videos. Annals of Tourism Research, 36(1), 24-40.

Urry, J. (1990). The Tourist Gaze. Leisure and Travel in Contemporary Societies. Collection Theory, culture \& society», London, Sage Publications.

Urry, J. (1988). Cultural change and contemporary holiday-making. Theory, culture \& society, 5(1), 35-55.

Vinzi, V. E., Chin, W. W., Henseler, J., \& Wang, H. (2010). Handbook of partial least squares (Vol. 201, No. 0). Berlin: Springer.

We are social (2019). Digital 2019: Spain. Recuperado de https://datareportal.com/reports/digital-2019-spain

Wong, P. P. W. (2018). Role of components of destination competitiveness in the relationship between customer-based brand equity and destination loyalty. Current Issues in Tourism, 21(5), 504-528.

Yang, Y., Liu, X., y Li, J. (2015). How customer experience affects the customer-based brand equity for tourism destinations. Journal of Travel \& Tourism Marketing, 32(sup1), S97S113. 
Zavattaro, S. M., Daspit, J. J., y Adams, F. G. (2015). Assessing managerial methods for evaluating place brand equity: A qualitative investigation. Tourism Management, 47, 11-21.

Zeithaml, V. A. (1988). Consumer perceptions of price, quality, and value: a means-end model and synthesis of evidence. Journal of marketing, 52(3), 2-22.

Zeithaml, V. A., y Bitner, M. J. (2000). Services marketing: Integrating customer focus across the firm. McGraw Hill.

Zeng, B., y Gerritsen, R. (2014). What do we know about social media in tourism? A review. Tourism Management Perspectives, 10, 27-36.

Anexo 1. Detalle ítems empleados

\begin{tabular}{|c|c|c|c|c|}
\hline Constructo & Indicador & Ítems & Media & $\begin{array}{l}\text { Desviación } \\
\text { Típica }\end{array}$ \\
\hline \multicolumn{5}{|c|}{$\begin{array}{l}\text { En relación a los contenidos sobre Goa en medios sociales que acabas de visualizar, indica cuál es tu } \\
\text { opinión respecto a las siguientes cuestiones: }\end{array}$} \\
\hline \multirow[t]{4}{*}{ Conocimiento } & AWA1 & $\begin{array}{l}\text { Goa es un destino que cuenta con buena } \\
\text { fama y reputación }\end{array}$ & 3,32 & 1,94 \\
\hline & AWA2 & $\begin{array}{l}\text { Sus características acuden a mi mente } \\
\text { rápidamente }\end{array}$ & 3,91 & 1,69 \\
\hline & AWA3 & Goa es un destino muy famoso & 2,41 & 1,34 \\
\hline & AWA4 & $\begin{array}{l}\text { He visto mucha publicidad } \\
\text { promocionándolo como destino de } \\
\text { vacaciones }\end{array}$ & 1,76 & 1,15 \\
\hline \multirow[t]{2}{*}{ Imagen } & IG1 & La imagen que tengo de Goa es mala/buena & 5,58 & 1,37 \\
\hline & IG2 & $\begin{array}{l}\text { La imagen que tengo de Goa es } \\
\text { negativa/positiva }\end{array}$ & 5,58 & 1,43 \\
\hline \multirow[t]{3}{*}{ Calidad } & QUA1 & $\begin{array}{l}\text { Goa proporciona al turista una calidad } \\
\text { constante }\end{array}$ & 3,45 & 1,84 \\
\hline & QUA2 & Goa proporciona experiencias de calidad & 4,25 & 1,90 \\
\hline & QUA3 & $\begin{array}{l}\text { Esperaría obtener un buen resultado de la } \\
\text { oferta de este destino }\end{array}$ & 5,24 & 1,17 \\
\hline \multirow[t]{3}{*}{ V Percibido } & VAL 1 & $\begin{array}{l}\text { Teniendo en cuenta lo que pagaría por este } \\
\text { viaje, merecería la pena visitarlo }\end{array}$ & 4,39 & 1,89 \\
\hline & VAL 2 & $\begin{array}{l}\text { El coste que asumiría por visitar este } \\
\text { destino, es una ganga en comparación con } \\
\text { los beneficios que obtendría al visitarlo }\end{array}$ & 3,42 & 1,96 \\
\hline & VAL 3 & Ofrece una buena relación calidad-precio & 3,26 & 2,25 \\
\hline \multirow[t]{3}{*}{$\begin{array}{l}\text { Lealtad } \\
\text { actitudinal }\end{array}$} & LOY1 & $\begin{array}{l}\text { Ese destino sería mi opción preferida a la } \\
\text { hora de elegir lugar de vacaciones }\end{array}$ & 2,91 & 1,48 \\
\hline & LOY2 & $\begin{array}{l}\text { Recomendaría a otros que visitaran este } \\
\text { destino }\end{array}$ & 4,04 & 1,79 \\
\hline & LOY3 & Tengo la intención de visitarlo en un futuro & 3,61 & 1,92 \\
\hline
\end{tabular}

$$
\text { Elaboración Propia }
$$

\section{CONTRIBUCIONES DE LAS AUTORAS:}

Autor 1: concepción original del trabajo y redacción.

Autor 2: revisión crítica y aprobación final de la versión a publicar.

Autor 3: revisión crítica y aprobación final de la versión a publicar. 